BMJ Open

Diabetes

Research

\& Care

\section{Primary care physicians' utilization of type 2 diabetes screening guidelines and referrals to behavioral interventions: a survey-linked retrospective study}

To cite: Mehta S, Mocarski M, Wisniewski T, et al. Primary care physicians' utilization of type 2 diabetes screening guidelines and referrals to behavioral interventions: a survey-linked retrospective study. BMJ Open Diab Res Care 2017;5:e000406. doi:10.1136/ bmjdrc-2017-000406

- Additional material is published online only. To view these files please visit the journal online (http://dx.doi. org/10.1136/bmjdrc-2017000406).

Parts of this research were presented as poster and/or oral presentations at American Public Health Association 144th Meeting, Denver, C0, USA; 9th World Congress on Prevention of Diabetes and Its Complications, Atlanta, GA, USA; and 31st Annual Clinical Conference on Diabetes (American Diabetes Association), Ponte Vedra Beach, FL, USA.

Received 22 February 2017 Revised 19 May 2017 Accepted 5 June 2017

\section{CrossMark}

${ }^{1}$ QuintilesIMS, Cambridge, Massachusetts, USA ${ }^{2}$ Novo Nordisk, Plainsboro, New Jersey, USA ${ }^{3}$ Emory University, Atlanta, Georgia, USA

Correspondence to Dr Kathleen Lang; kathy.lang@quintiles.com

\section{ABSTRACT}

Objective To assess primary care physicians' (PCPs) knowledge of type 2 diabetes screening guidelines (American Diabetes Association (ADA) and 2008 US Preventive Services Task Force (USPSTF)), the alignment between their self-reported adherence and actual practice, and how often PCPs recommended diabetes prevention and self-management education programs (DPP/DSME).

Research design and methods An online survey of PCPs to understand knowledge and adherence toward use of USPSTF/ADA guidelines and recommendation of DPP/ DSME. Patient data from electronic medical records (EMRs) for each PCP were used to identify rates of screening in eligible patients as per guidelines and the two sources were compared to assess concordance.

Results 0 305 surveyed physicians, 38\% reported use of both guidelines (33\% use ADA only, $25 \%$ USPSTF only). Approximately one-third of physicians who reported use of USPSTF/ADA guidelines had non-concordant EMR data. Similarly, while most PCPs reported they are 'very likely' to screen patients with risk factors listed in guidelines, for each criterion at least one-fourth (24\%) of PCPs survey responses were non-concordant with EMRs. PCPs reported they provide referral to DPP and DSME on average to $45 \%$ and $67 \%$ of their newly diagnosed patients with pre-diabetes and diabetes, respectively.

Conclusion Findings show disconnect between PCPs' perceptions of adherence to screening guidelines and actual practice, and highlight limited referrals to DPP/ DSME programs. More research is needed to understand barriers to guideline consistent screening and uptake of DPP/DSME, particularly in light of recent policy changes such as the linking USPSTF criteria to reimbursement and expected Medicare DPP reimbursement in 2018.

\section{INTRODUCTION}

The prevalence of diabetes mellitus, largely type 2 diabetes mellitus, has reached epidemic proportions in the USA. ${ }^{12}$ In 2012 , up to 29.1 million people were reported to have diabetes of which $28 \%$ were previously undiagnosed, ${ }^{1}$ with medical costs estimated to be $\$ 245$ billion. $^{3}$ Furthermore, 86 million
Americans aged $\geq 20$ years had pre-diabetes, with $90 \%$ unaware of it. ${ }^{1}$

Early detection and management of diabetes and pre-diabetes are fundamental to preventing and treating diabetes. Expert groups, such as the US Preventive Services Task Force (USPSTF) and American Diabetes Association (ADA), have recommended screening for diabetes and pre-diabetes (see online supplementary table S1). ${ }^{4-7}$ However, previous retrospective studies have shown suboptimal screening rates $(46 \%-85 \%)$ in populations who meet ADA and/or 2008 USPSTF guidelines criteria. ${ }^{28-11}$ Furthermore, the reasons behind guideline inconsistent screening are unknown, in particular, how physicians view the guidelines and how their views relate to actual utilization. Of additional interest for this study was to understand how primary care physicians (PCPs) treat patients newly diagnosed with pre-diabetes and diabetes.

The specific objectives of this study included: (1) to assess PCPs' knowledge and attitude toward type 2 diabetes screening guidelines and preferred screening method; (2) to examine the extent of alignment (concordance) between PCPs' self-reported behavior and their actual screening practices (real-world evidence obtained from electronic medical records (EMR)); and (3) to assess the extent of PCP-driven referral to diabetes prevention and self-management education programs (DPP/DSME).

The guidelines considered in this study included the ADA and the 2008 USPSTF guidelines which were in effect during the study period. The 2015 guidelines were not evaluated as they were not finalized until after the study was in progress. 


\section{Significance of this study}

What is already known about this subject?

- Expert groups, such as the US Preventive Services Task Force (USPSTF) and American Diabetes Association (ADA), have recommended screening guidelines for diabetes and pre-diabetes.

- Despite established national screening guidelines in USA, suboptimal screening rates are reported in previous literature but the reasons behind guideline inconsistent screening are unknown; in particular how primary care physicians (PCPs) perceive these guidelines and whether physician perceptions of their adherence to guidelines is consistent with actual rates of adherence in their individual practices.

What are the new findings?

- In the current study, many PCPs reported they rely on ADA/2008 USPSTF diabetes screening guidelines to screen patients at risk. However, one-third of PCPs that indicated that they used guidelines did not have electronic medical records data that showed guideline use.

> Nearly all PCPs noted they provided diet and lifestyle coaching to patients newly diagnosed with pre-diabetes and diabetes. However, PCPs reported referring, on average, only $67 \%$ of patients to Diabetes Self-Management Education programs upon diagnosis, and that rate of referral varied by patient's $\mathrm{HbA1C}$. Referral to the Diabetes Prevention Program was even lower, with PCPs indicating that, on average, only $45 \%$ of patients are referred.

How might these results change the focus of research or clinical practice?

> Findings emphasize importance of:

- Developing educational efforts to improve the awareness of diabetes screening guidelines, particularly USPSTF's 2015 update which is linked to insurance coverage.

- Adoption of quality measures to encourage screening and subsequent appropriate referral to diabetes prevention and management programs.

- Further research is needed to understand barriers to guideline consistent diabetes screening in primary care and uptake of diabetes prevention and management programs.

\section{METHODS}

\section{Study design and sample}

An online survey of PCPs linked with utilization data from EMRs of patients treated by each surveyed PCP was conducted.

\section{Data source}

QuintilesIMS' proprietary EMR database was used to recruit PCPs for the online survey. Eligible PCPs were participants in the Medical Quality Improvement Consortium (MQIC), a network of ambulatory care providers that had previously expressed an interest in research activities. The MQIC network comprised over 650 member institutions, including over 39,000 providers and over 37 million patient lives, with over 17 million patients regularly using services.

Patient-level data from the surveyed PCPs (linked by National Provider Identified (NPI) numbers) were then extracted from the EMR database. Patient-level de-identified and Health Insurance Portability and Accountability Act (HIPAA) compliant records provided researchers with demographics, vital signs, medical diagnoses, diagnostic tests/results, procedures, insurance information, and prescription details in a longitudinal patient medical record.

\section{Survey respondent selection and recruitment}

The study was approved by New England International Review Board. The PCPs NPI numbers were identified and used to obtain contact details from the publicly available Center for Medicare and Medicaid Services (CMS) NPI Registry Data or MQIC Sites' Points of Contact. The PCPs were sent invitations to participate in the survey through emails or US mail. Identified PCPs were provided with a description of the study, survey instructions, and a web-based link to an online survey portal. Electronically signed informed consent was collected before proceeding with the survey. The intent to perform concordance between PCPs' responses and evidence from EMR was not disclosed to participants as it may have biased the results of the study; this was noted in the Institutional Review Board (IRB) submission. Only PCPs with at least 3 years of experience and providing care for adults ( $\geq 18$ years) were allowed to participate in the survey.

\section{Surveyed PCPs' patient selection and follow-up}

EMR data for all patients associated with each surveyed PCP were extracted. Study patients who met the following inclusion criteria were included in the study: (1) aged $\geq 18$ years who had 4 or more years of activity with the surveyed physician between January 2009 and September 2014, with at least one office visit in those 4 years; (2) eligible for diabetes screening tests based on ADA or 2008 USPSTF criteria between January 2010 and September 2011 (see online supplementary table S2 for details on screening guideline criteria applied to EMR database); and (3) having at least one activity in the year before they were observed to be eligible for diabetes screening. The time frame to observe patient's screening eligibility was January 2010 through September 2011, to ensure a subsequent 3-year time interval to observe receipt of the diabetes screening test (guidelines recommend screening every 3 years). This approach captured some patients who already had conditions making them eligible for screening (prevalent) as well as those who became eligible after study entry (incident). Patients with any of the following criteria were excluded: (1) evidence of pregnancy or gestational or type 1 diabetes during study period; and (2) diagnosis of pre-diabetes or diabetes or use of antidiabetic medications in the 1-year baseline. The patients eligible for screening were followed for 3 years to examine if they received diabetes screening test. The types of screening test included fasting or random plasma glucose test, oral glucose tolerance test, and HbA1C test. 
Study measures

Survey measures

The following areas were covered by the physician survey: (1) demographics and practice characteristics, (2) preferred screening test, (3) factors contributing to their decision to screen (i.e., clinical experience, screening guidelines, prompts from EMR or other), (4) which guidelines they most often use (i.e., USPSTF, ADA or other), and how often they use these guidelines (i.e., $100 \%, \geq 70 \%, \geq 50 \%$ or $<50 \%$ of the time), and (5) attitude toward USPSTF and ADA individual criteria. The PCPs were asked to select response options on a scale from 0 to 10 , with 0 being 'Not at all likely' and 10 being 'Extremely likely,' which was used to measure likelihood to screen patients with the following characteristics: (A) USPSTF criteria: blood pressure $\geq 135 / 80 / 80 \mathrm{~mm} \mathrm{Hg}$; (B) ADA criteria: patients 18-45 years old, overweight/ obese (body mass index $\geq 25 \mathrm{~kg} / \mathrm{m}^{2}$ ) and having additional risk factors (listed in online supplementary table S1). The physicians were also asked to report how often they recommend diet and lifestyle coaching or provide referral to DPP and DSME/DSMS (diabetes self-management support). Physicians who reported that their treatment varies by severity level in patients newly diagnosed with type 2 diabetes were asked to report treatment approaches by severity.

\section{EMR-based physician level concordance measures}

To assess alignment between self-reported use of ADA/ USPSTF guidelines and evidence from EMR, the following measure was calculated for each physician:

\section{$p_{i, k}^{\prime}=\frac{\text { No. of patients receiving screening under guideline } k}{\text { No. of patients eligible for screening under guideline } k}$}

The index $i$ represents individual physician, and the

$k$ represents different screening guidelines. In order to estimate concordance between the physician's self-reported and actual adherence to guidelines, the answers from the survey (use of USPSTF/ADA either $100 \%$, $\geq 70 \%, \geq 50 \%$, or $<50 \%$ of the time) were compared with $p_{i, k}^{\prime}$.

Additionally, a series of measures were calculated to measure concordance with respect to self-reported likelihood to screen patients with individual USPSTF/ADA criteria as shown below:

\section{$p_{i, j}=\frac{\text { No. of patients receiving screening under criteria } j}{\text { No. of patients eligible for screening under criteria } j}$}

The index $j$ represents the different screening criteria. Each survey question scale related to screening criteria was assumed to represent a percentage between $0 \%$ and $100 \%$, which was compared with $p_{i, j}$ to estimate concordance (see details in the Statistical analyses section). Two of the survey criteria (physical inactivity and history of gestational diabetes or given birth to baby $>9 \mathrm{lb}$ ) were not compared due to unavailability of information in EMR.

\section{Statistical analyses}

Survey measures were summarized in a descriptive manner (counts (percentages) or means (SD)). Multivariable logistic regression models were used to assess whether adherence to USPSTF and ADA screening guidelines (self-reported guidelines they most often use) differed by specific physician and practice characteristics. For the concordance analysis, physicians were categorized as: (1) concordant (following screening guidelines) (e.g., they say they frequently follow guidelines and the evidence from the EMR supports this), (2) concordant (but not following guidelines) (e.g., they say they less frequently follow guidelines and the evidence from the EMR supports this), (3) non-concordant (e.g., they say they frequently follow guidelines and the evidence from EMR does not support this), and (4) flagged (e.g., they say they do not follow guidelines or less frequently use guidelines and the evidence from EMR suggests that they actually do follow guidelines (had higher screening rates)).

To divide physicians into the above four categories for measuring adherence to USPSTF/ADA, a cut-off value of $50 \%$ was used (i.e., if a physician reported they use USPSTF guidelines $\geq 50 \%$ of the time and if $\geq 50 \%$ of their USPSTF eligible patients $\left(p_{i, k}^{\prime}\right)$ received screening test, they were categorized as concordant). For measuring concordance with respect to individual criteria, a cut-off value of self-reported response $\geq 50 \%$ (likelihood to screen) and percentage of patients screened $\geq 50 \%\left(p_{i, j}\right)$ was used to define concordant.

\section{RESULTS}

\section{Surveyed physician's characteristics and patient sample}

A total of 305 PCPs provided complete survey responses (response rate: 2.4\%). Table 1 provides details on survey respondents' demographics and practice characteristics. Fifty-six percent were male, $72 \%$ white and majority $(60 \%)$ indicated they prefer HbA1C test to conduct screening. The EMR patient sample was obtained for 281 surveyed physicians. After applying inclusion/exclusion criteria, a total of 123,990 patients were included in the study cohort and were flagged as eligible for screening. About $71 \%(\mathrm{n}=87,646)$ received a diabetes screening test within 3 years of follow-up (see details in online supplementary table S3).

\section{PCP's knowledge and attitude related to diabetes screening guidelines and concordance with actual practice}

Table 1 also shows results obtained from the survey on physicians' screening behavior. Of physicians who reported that they rely on screening guidelines ( $\mathrm{n}=233)$, around $71 \%$ reported they rely on ADA and $64 \%$ on USPSTF guidelines. Twenty-six percent of those who rely on guidelines reported they rely on them $100 \%$ of the time. Over half reported they rely on guidelines $\geq 70 \%$ (53\%) and one-sixth reported 


\section{Table 1 Surveyed PCP characteristics}

\begin{tabular}{lll}
\hline Characteristic & Total & \\
\hline $\begin{array}{l}\text { Gender, } \mathrm{n}(\%) \\
\text { Male }\end{array}$ & & \\
\hline Female & 172 & $(56)$ \\
Race/ethnicity, $\mathrm{n}(\%)$ & 133 & $(44)$ \\
$\quad$ Asian & & \\
\hline Black & 42 & $(14)$ \\
\hline Hispanic & 15 & $(5)$ \\
\hline White & 11 & $(4)$ \\
\hline Other & 221 & $(72)$ \\
\hline
\end{tabular}

Age category, $\mathrm{n}(\%)$

$\begin{array}{lll}25-34 \text { years } & 34 & (11) \\ 35-44 \text { years } & 118 & (39) \\ 45-54 \text { years } & 84 & (28) \\ \geq 55 \text { years } & 69 & (23)\end{array}$

Region, $\mathrm{n}(\%)$

$\begin{array}{lll}\text { East } & 94 & (31) \\ \text { Midwest } & 50 & (16) \\ \text { South } & 94 & (31) \\ \text { West } & 67 & (22)\end{array}$

Medical practice setting, $n(\%)$

$\begin{array}{lll}\text { Single specialty } & 131 & (43) \\ \text { Multispecialty or group practice } & 163 & (53) \\ \text { Other } & 11 & \text { (4) }\end{array}$

Years in practice

$\begin{array}{lll}3 \text { to }<10 & 121 & (40) \\ 10 \text { to }<15 & 50 & (16) \\ 15 \text { to }<20 & 47 & (15) \\ \geq 20 & 87 & (29)\end{array}$

Number of physicians in practice, $\mathrm{n}(\%)$

$\leq 25$

26-99 78

$\geq 100$

Area of practice, $n(\%)$

$\begin{array}{lll}\text { Rural } & 109 & (36) \\ \text { Urban } & 141 & (46) \\ \text { Suburban } & 55 & (18)\end{array}$

Main insurance type, $\mathrm{n}(\%)$

$\begin{array}{lll}\text { Medicaid } & 55 & (18) \\ \text { Medicare } & 67 & (22) \\ \text { Commercial } & 164 & (54) \\ \text { Unknown } & 19 & (6)\end{array}$

Preferred screening method for pre-

diabetes/diabetes, $\mathrm{n}(\%)$

$\begin{array}{lll}\text { HbA1c test } & 182 & (60) \\ \text { Fasting plasma glucose test } & 108\end{array}$

Continued

\begin{tabular}{|c|c|c|}
\hline Characteristic & Total & \\
\hline Random plasma glucose test & 9 & (3) \\
\hline Oral glucose tolerance test & 5 & $(2)$ \\
\hline $\begin{array}{l}\text { Other ( } \mathrm{HbA} 1 \mathrm{C} \text { and fasting blood } \\
\text { glucose) }\end{array}$ & 1 & $(0)$ \\
\hline \multicolumn{3}{|l|}{$\begin{array}{l}\text { Factors that influence decision to screen } \\
\text { for diabetes, } \mathrm{n}(\%)\end{array}$} \\
\hline Personal clinical experience & 239 & $(78)$ \\
\hline $\begin{array}{l}\text { Prompts from electronic medical record } \\
\text { system }\end{array}$ & 51 & $(17)$ \\
\hline Screening guidelines & 233 & (76) \\
\hline Other & 24 & (8) \\
\hline \multicolumn{3}{|l|}{$\begin{array}{l}\text { Physician preference for screening } \\
\text { guidelines, } \mathrm{n}(\%)\end{array}$} \\
\hline USPSTF & 148 & $(64)$ \\
\hline ADA & 166 & (71) \\
\hline USPSTF and ADA & 89 & (38) \\
\hline USPSTF only & 59 & $(25)$ \\
\hline ADA only & 77 & (33) \\
\hline Other & 4 & $(2)$ \\
\hline None & 3 & $(1)$ \\
\hline \multicolumn{3}{|l|}{$\begin{array}{l}\text { Physician's use of screening guidelines*, } \\
\text { n (\%) }\end{array}$} \\
\hline $100 \%$ of the time & 61 & $(26)$ \\
\hline$\geq 70 \%$ of the time & 124 & (53) \\
\hline$\geq 50 \%$ of the time & 39 & $(17)$ \\
\hline$<50 \%$ of the time & 9 & $(4)$ \\
\hline \multicolumn{3}{|l|}{ USPSTF, n (\%) } \\
\hline $100 \%$ of the time & 23 & (16) \\
\hline$\geq 70 \%$ of the time & 96 & $(65)$ \\
\hline$\geq 50 \%$ of the time & 25 & $(17)$ \\
\hline$<50 \%$ of the time & 4 & (3) \\
\hline \multicolumn{3}{|l|}{ ADA, n (\%) } \\
\hline $100 \%$ of the time & 32 & $(19)$ \\
\hline$\geq 70 \%$ of the time & 108 & $(65)$ \\
\hline$\geq 50 \%$ of the time & 22 & $(13)$ \\
\hline$<50 \%$ of the time & 4 & (2) \\
\hline
\end{tabular}

${ }^{*}$ Questions asked to only those physicians who reported screening guidelines influence their decision to screen $(n=233)$. Percentages reported out of total 233 physicians.

ADA, American Diabetes Association; PCP, primary case physician; USPSTF, US Preventive Services Task Force.

they rely on them $\geq 50 \%$ of the time $(17 \%)$. Table 2 shows results from multivariable logistic regression assessing association between physician characteristics and adherence to USPSTF and ADA guidelines to screen for diabetes. The physician's age was found to be a significant predictor of adherence to USPSTF guidelines, with physicians in age group 35-44 years (OR $0.25,95 \% \mathrm{CI} 0.09$ to 0.68 ) and 
Table 2 Factors associated with adherence to USPSTF and ADA guidelines

\begin{tabular}{|c|c|c|c|c|c|c|}
\hline \multirow[b]{3}{*}{ Physician Characteristics } & \multicolumn{3}{|c|}{ USPSTF } & \multicolumn{3}{|l|}{ ADA } \\
\hline & \multicolumn{6}{|c|}{ Multivariable association } \\
\hline & $\begin{array}{l}\text { Odds } \\
\text { ratio } \\
\text { (OR) }\end{array}$ & $95 \% \mathrm{Cl}$ & p Value & OR & $95 \% \mathrm{Cl}$ & p Value \\
\hline \multicolumn{7}{|l|}{ Gender } \\
\hline Male & Ref & & & Ref & & \\
\hline Female & 0.93 & 0.54 to 1.58 & 0.7873 & 1.46 & 0.85 to 2.49 & 0.1678 \\
\hline \multicolumn{7}{|l|}{ Race/ethnicity } \\
\hline White & Ref & & & Ref & & \\
\hline Asian & 1.12 & 0.52 to 2.40 & 0.7774 & 1.92 & 0.90 to 4.11 & 0.0938 \\
\hline Black & 0.45 & 0.13 to 1.59 & 0.2130 & 0.87 & 0.25 to 2.98 & 0.8214 \\
\hline Hispanic & 0.94 & 0.24 to 3.68 & 0.9271 & 0.29 & 0.07 to 1.19 & 0.0863 \\
\hline Other & 0.85 & 0.27 to 2.69 & 0.7829 & 1.81 & 0.51 to 6.47 & 0.3602 \\
\hline \multicolumn{7}{|l|}{ Age category (years) } \\
\hline $25-34$ & Ref & & & Ref & & \\
\hline $35-44$ & 0.25 & 0.09 to 0.68 & $0.0062^{*}$ & 1.26 & 0.52 to 3.05 & 0.6085 \\
\hline $45-54$ & 0.26 & 0.08 to 0.90 & $0.0334^{*}$ & 0.95 & 0.30 to 3.02 & 0.9265 \\
\hline $55-64$ & 0.38 & 0.09 to 1.68 & 0.2023 & 0.68 & 0.16 to 2.86 & 0.5989 \\
\hline$\geq 65$ & 0.34 & 0.04 to 2.94 & 0.3287 & 1.09 & 0.12 to 9.11 & 0.9389 \\
\hline \multicolumn{7}{|l|}{ Years in practice } \\
\hline 3 to $<10$ & Ref & & & Ref & & \\
\hline 10 to $<15$ & 1.11 & 0.51 to 2.41 & 0.7937 & 0.75 & 0.34 to 1.64 & 0.4698 \\
\hline 15 to $<20$ & 0.86 & 0.34 to 2.15 & 0.7447 & 1.07 & 0.42 to 2.71 & 0.8879 \\
\hline$\geq 20$ & 0.72 & 0.24 to 2.21 & 0.5701 & 1.70 & 0.55 to 5.22 & 0.3576 \\
\hline \multicolumn{7}{|l|}{ Practice characteristics } \\
\hline \multicolumn{7}{|l|}{ Medical practice setting } \\
\hline Multispecialty or group practice & Ref & & & Ref & & \\
\hline Single specialty & 0.94 & 0.55 to 1.62 & 0.8296 & 0.98 & 0.57 to 1.69 & 0.9450 \\
\hline Other & 0.60 & 0.15 to 2.41 & 0.4726 & 1.22 & 0.31 to 4.78 & 0.7764 \\
\hline \multicolumn{7}{|l|}{ Number of physicians in practice } \\
\hline$\leq 25$ & Ref & & & Ref & & \\
\hline $26-99$ & 0.97 & 0.52 to 1.79 & 0.9153 & 0.82 & 0.45 to 1.52 & 0.5363 \\
\hline$\geq 100$ & 0.90 & 0.48 to 1.69 & 0.7394 & 1.05 & 0.56 to 1.97 & 0.8891 \\
\hline \multicolumn{7}{|l|}{ Area of practice } \\
\hline Urban & Ref & & & Ref & & \\
\hline Suburban & 1.54 & 0.82 to 2.76 & 0.1462 & 1.33 & 0.74 to 2.39 & 0.3346 \\
\hline Rural & 0.84 & 0.38 to 1.84 & 0.6574 & 1.61 & 0.73 to 3.52 & 0.2368 \\
\hline \multicolumn{7}{|l|}{ Region } \\
\hline East & Ref & & & Ref & & \\
\hline Midwest & 1.12 & 0.52 to 2.43 & 0.7651 & 0.95 & 0.44 to 2.06 & 0.9032 \\
\hline South & 1.77 & 0.93 to 3.48 & 0.0974 & 1.00 & 0.51 to 1.96 & 0.9963 \\
\hline West & 1.21 & 0.61 to 2.43 & 0.5821 & 1.41 & 0.70 to 2.84 & 0.3409 \\
\hline \multicolumn{7}{|l|}{ Main insurance type } \\
\hline Commercial & Ref & & & Ref & & \\
\hline \multirow[t]{2}{*}{ Medicaid } & 1.33 & 0.65 to 2.70 & 0.4384 & 1.88 & 0.90 to 3.91 & 0.0913 \\
\hline & & & & & & Continued \\
\hline
\end{tabular}


Table 2 Continued

\begin{tabular}{|c|c|c|c|c|c|c|}
\hline \multirow[b]{3}{*}{ Physician Characteristics } & \multicolumn{3}{|c|}{ USPSTF } & \multicolumn{3}{|l|}{ ADA } \\
\hline & \multicolumn{6}{|c|}{ Multivariable association } \\
\hline & $\begin{array}{l}\text { Odds } \\
\text { ratio } \\
\text { (OR) }\end{array}$ & $95 \% \mathrm{Cl}$ & p Value & OR & $95 \% \mathrm{Cl}$ & p Value \\
\hline Medicare & 0.54 & 0.28 to 1.05 & 0.0702 & 0.65 & 0.34 to 1.23 & 0.1856 \\
\hline Unknown & 0.60 & 0.20 to 1.79 & 0.3615 & 1.45 & 0.48 to 4.40 & 0.5147 \\
\hline $\begin{array}{l}\text { Number of patients seen monthly in current } \\
\text { practice }\end{array}$ & 1.00 & 1.00 to 1.00 & 0.5702 & 1.00 & 1.00 to 1.00 & 0.9473 \\
\hline $\begin{array}{l}\text { Percent of patients with diabetes seen } \\
\text { monthly }\end{array}$ & 1.01 & 0.99 to 1.02 & 0.5823 & 1.03 & 1.00 to 1.04 & $0.0017^{*}$ \\
\hline \multicolumn{7}{|l|}{ Importance of patient's out-of-pocket cost } \\
\hline Not important & Ref & & & Ref & & \\
\hline Slightly important & 1.19 & 0.55 to 2.57 & 0.6533 & 1.27 & 0.59 to 2.70 & 0.5436 \\
\hline Somewhat important & 1.11 & 0.53 to 2.31 & 0.7755 & 0.76 & 0.36 to 1.58 & 0.4585 \\
\hline Very important & 2.31 & 1.01 to 5.27 & $0.0462^{*}$ & 0.78 & 0.34 to 1.76 & 0.5431 \\
\hline Extremely important & 2.05 & 0.32 to 1.31 & 0.4465 & 0.86 & 0.16 to 4.62 & 0.8618 \\
\hline
\end{tabular}

*Significant at $\mathrm{p}$ value $<0.05$. ADA, American Diabetes Association; USPSTF, US Preventive Services Task Force.

$45-55$ years (OR $0.26,95 \%$ CI 0.08 to 0.90 ) less likely to report they use USPSTF guidelines most often compared with 25-44 years group. Also, physicians who reported that patient's out-of-pocket expense is very important in their decision to conduct screening were found to be more likely to use USPSTF guidelines (OR 2.31, 95\% CI 1.01 to 5.27). For ADA guidelines, physicians who reported higher percent of patients with diabetes seen monthly were more likely to report adherence to ADA guidelines (OR 1.03, $95 \%$ CI 1.00 to 1.04 ).

Figure 1 shows the distribution of concordant and non-concordant physicians with respect to overall use of USPSTF and ADA guidelines. For the USPSTF guidelines, $45 \%(n=118)$ of PCPs indicated that they screened according to USPSTF guidelines at least $50 \%$ of the time (concordant; non-concordant); however, 29\% ( $\mathrm{n}=34$ ) of these physicians had EMR data which showed non-concordance (that they used USPSTF less than $50 \%$ of the time). Similarly, for ADA criteria, $52 \%$ ( $n=145$ ) of physicians stated in the survey that they used ADA criteria (concordant; non-concordant); however, 33\% $(n=45)$ of these physicians had non-concordant EMR data. Additionally, for both sets of screening criteria, nearly one-third of physicians $(36 \%$ for USPSTF and $32 \%$ for ADA) note that they use each criteria less than $50 \%$ of the time, when they actually use the guidelines far more frequently (flagged).

Figure 2 shows the distribution of concordant versus non-concordant physicians with respect to attitude toward individual guideline criteria. For each criterion, the majority of physician responses were concordant $(56 \%-$ $76 \%$ ) (meaning that they reported in the survey that they screened patients meeting that criterion, and the EMR showed that this was true). The proportion of non-concordant physicians ranged from $24 \%$ to $38 \%$ (those reporting using the guidelines, but EMR data showed they did not) with smallest percentage observed for family history of diabetes and history of elevated HbA1C (24\%), and the highest for acanthosis nigricans (38\%).

\section{PCP's referral to diabetes prevention and management programs}

Figure 3 shows the average percentage of patients who were recommended behavioral interventions self-reported by PCPs. PCPs reported that they provide diet and lifestyle coaching to almost all patients with pre-diabetes (average survey response was that $95 \%$ of their patients would receive coaching) but provide referral to DPP to less than half of patients ( $45 \%$ of patients). Similarly, physicians reported that they recommend diet and lifestyle coaching to nearly all their patients with diabetes (96\% of patients) followed by referral to DSME/DSMS $(67 \%)$. Almost all physicians $(\mathrm{n}=290,97 \%)$ reported their treatment approaches for patients newly diagnosed with diabetes vary by severity level. Diet and lifestyle coaching was provided to all patients with type 2 diabetes irrespective of their severity level, whereas a statistically significant increase in rates of referral to DSME/DSMS was observed with an increase in diabetes severity (range: $45 \%-82 \%$, p value $<0.05$ ).

\section{DISCUSSION}

Amidst growing national diabetes burden and cases of undiagnosed diabetes, ${ }^{1}$ our study provides information on physicians' knowledge and attitude toward screening guidelines and also provides real-world evidence on their adherence to these guidelines as well as referral patterns for behavioral interventions. 
USPSTF Guidelines
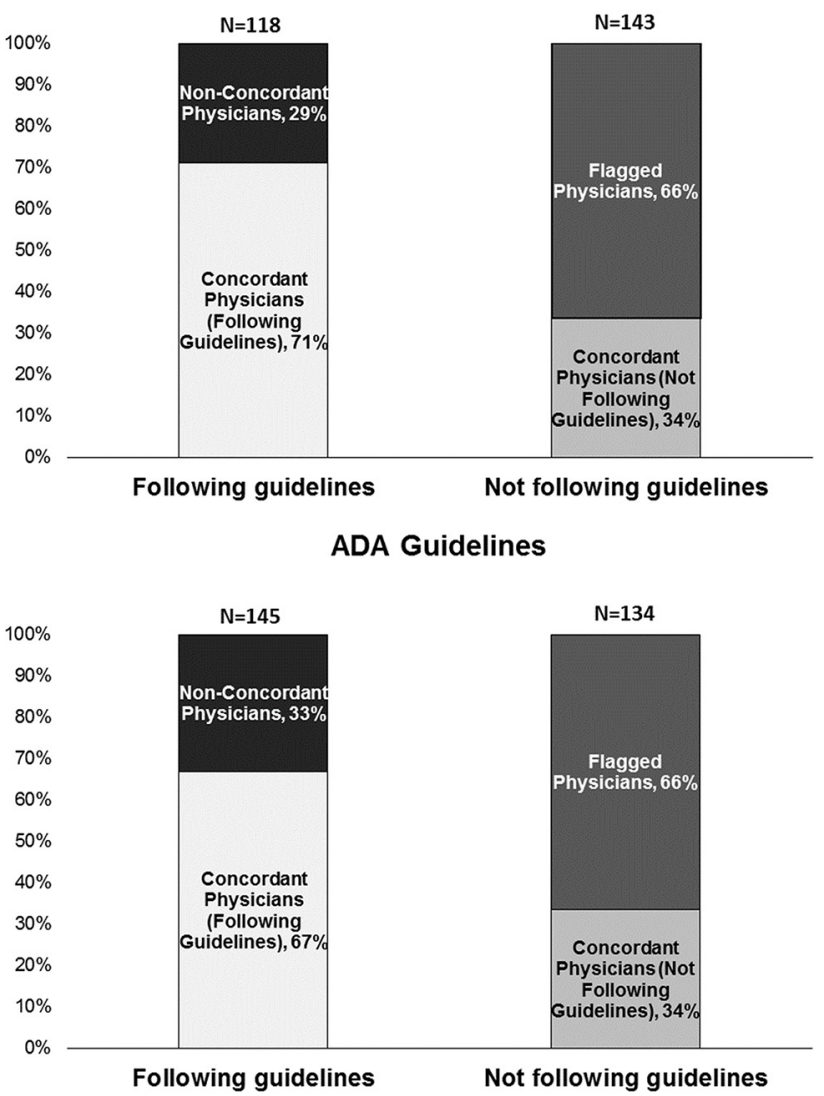

Figure 1 Relationship between self-reported adherence to USPSTF/ADA guidelines and evidence from EMR. $†$ The concordance analysis was performed on only 281 surveyed physicians due to unavailability of eligible patients in EMR for remaining physicians. Therefore, the total percentage of physicians who followed USPSTF/ ADA guidelines (concordant and non-concordant) is lower than that reported in table 1 (USPSTF: $64 \%$, ADA: 71\%). ADA, American Diabetes Association; EMR, electronic medical records; USPSTF, US Preventive Services Task Force.

Our first objective, to determine PCPs' knowledge and attitudes toward screening guidelines and their preferred screening method, showed that many PCPs (76\%) consider screening guidelines as an important factor to influence their decision to screen. However, nearly the same amount, (78\%), note that they rely on personal clinical experience. Therefore, physicians are relying on more than just guidelines at the time the decision to screen is made, which may be the reason for the disconnect between PCPs' self-reported adherence to guidelines and actual practice. The majority of PCPs also noted that HbAlc was their preferred screening test $(60 \%)$.

Our second objective, related to examining the extent of concordance between PCPs' self-reported screening and their actual behavior, showed about one-third of PCPs who reported following guidelines actually did not. However, when adherence to individual screening criteria was considered, concordance was higher $(56 \%-76 \%)$.
The higher concordance rates for individual screening criteria reflect that many physicians who reported they do not follow USPSTF/ADA guidelines were however more likely to adhere to individual criteria (survey questionnaire did not reveal they are part of USPSTF/ADA guidelines). The findings indicate that many physicians may not be aware of USPSTF/ADA guidelines and are likely relying on clinical experience and other sources; however, they do appear to be using the fundamental concepts encoded in the guidelines, and thus, resulting in higher concordance rates with respect to likelihood to screen.

Our third objective, to examine the extent of PCP-driven referral to DPP/DSME programs, showed that while most patients newly diagnosed with pre-diabetes and diabetes received diet and lifestyle coaching, less than half of patients with pre-diabetes and only two-thirds of patients with diabetes were referred to DPP or DSME/DSMS, respectively. Among patients diagnosed with diabetes, referral rates varied by HbA1C level, with those with an HbA1C less than $9 \%$ being referred less than half of the time compared with those with HbA1C greater than $9 \%$.

Several previous studies have examined screening rates in US adults who meet ADA/USPSTF criteria. ${ }^{28-11}$ Previous studies reported between $42 \%$ and $85 \%$ of patients eligible as per ADA and/or USPSTF criteria received diabetes screening tests. ${ }^{281011}$ The present study which showed that $71 \%$ of eligible patients were screened within 3 years of exhibiting a risk factor for diabetes is consistent with this finding.

While a previous study has suggested that screening efforts should be targeted to patients with rare conditions, such as Polycystic Ovarian Syndrome (PCOS), due to the higher rate of case detection, ${ }^{2}$ the current study showed that this may not be occurring. The percentage of non-concordant physicians was among the highest for those with a history of the rare disease acanthosis nigricans (38\%). Though the non-concordance rate was lower for women with PCOS, it was still at $26 \%$.

Despite expert group recommendation on providing referral to diabetes prevention and education programs, our study found that compared with diet and lifestyle coaching, physicians provide far fewer referrals (45\%-67\%) to well-established behavioral intervention programs. Few survey studies have been conducted to identify patient and physician barriers to access DSME and lifestyle intervention; however, gaining an understanding of these barriers and their impact on access and uptake is critical to ensuring that patients receive optimal care. $^{12-16}$

\section{Strengths}

The characteristics of 305 PCPs who completed the survey are somewhat comparable to characteristics of all physicians in USA. ${ }^{17} 18$ Overall, US PCPs are $66 \%$ male, around $55 \%$ are between 36 and 55 years old, and $54 \%$ are white. Our sample consisted of over half male, majority white $(72 \%)$ and $67 \%$ in age group of $35-54$ years. Sixty percent 


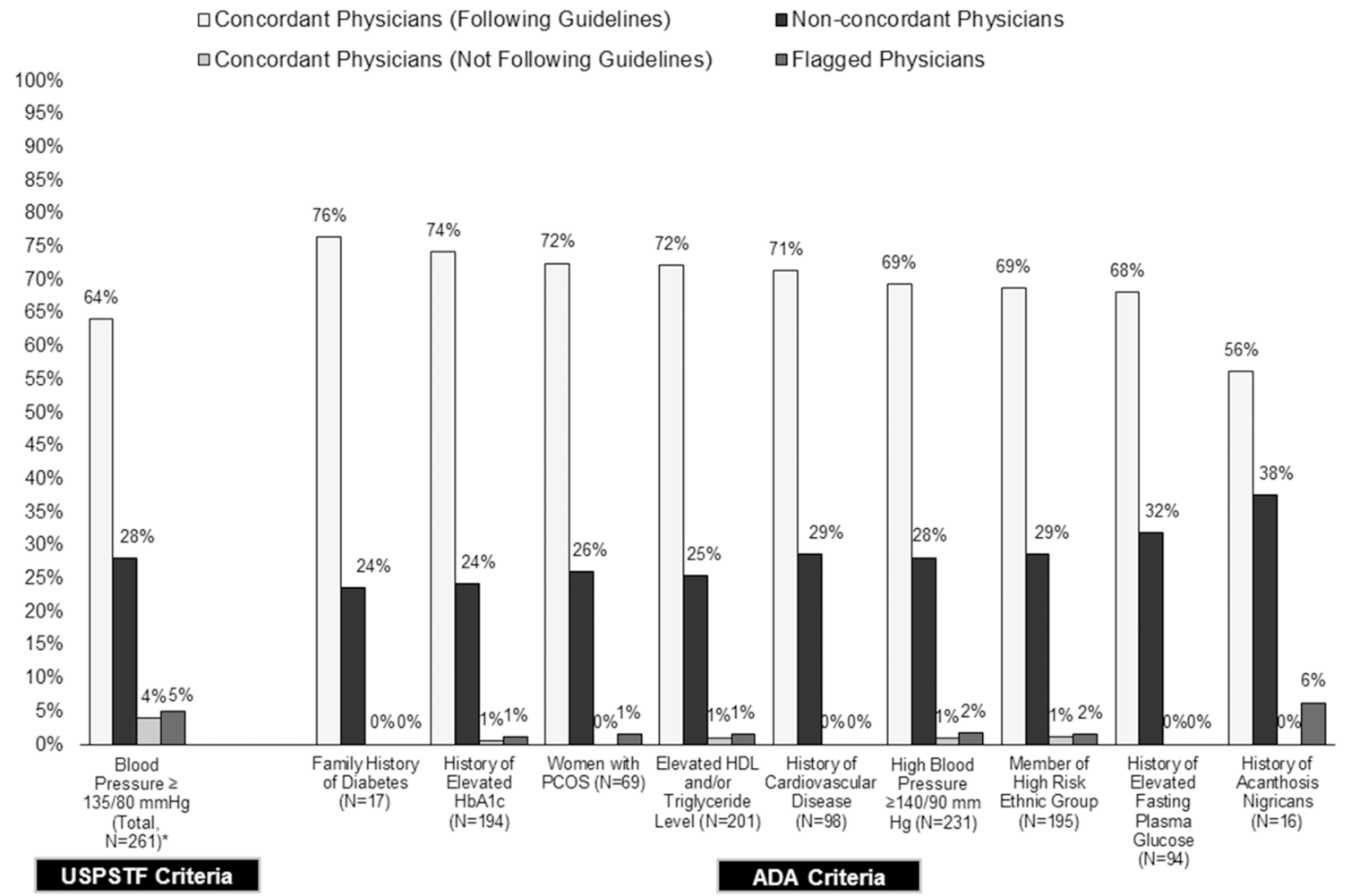

Figure 2 Concordance between self-reported likelihood to screen eligible patients as per ADA/USPSFT criteria and evidence from EMR. ADA, American Diabetes Association; EMR, electronic medical records; HDL, high-density lipoprotein; PCOS, Polycystic Ovarian Syndrome; USPSTF, US Preventive Services Task Force.

of physicians had $10+$ years practice experience with a majority having a multispecialty or group practice (53\%) and predominantly treating commercial patients $(54 \%)$. Therefore, findings could be generalizable to overall US PCPs. Additionally, use of enriched Q-EMR database enabled us to assess concordance with the majority of individual guidelines criteria. A large cohort of screening eligible patients was identified and followed up for at least 3 years to examine screening rates.

\section{Limitations}

The prospective survey portion of the study may suffer from limitations common to survey analyses including non-response bias and recall bias. Likewise, the retrospective analysis using EMR may suffer from limitations common to retrospective database analyses including possible missing and incorrect data in addition to the fact that data are not collected solely for research purposes. Gaps in the medical record will result whenever patients receive care from other providers although documentation is not provided to the original physician.

The concordance analysis was limited to the information available from EMR and thus results may not be generalized to all screening guideline criteria. There are free-text data in EMR that are not available for analysis due to complexities associated with such coding and potential identification of protected health information. The concordance analysis for referral to DPP/DSME was not conducted due to unavailability in EMR. Additionally, the study did not look at the rates of inappropriate screening (i.e., screening rates in patients not eligible as per screening guidelines) that may help to compare and contrast real-world screening behaviors. Additionally, the study did not assess care provided by nurse practitioners or physician assistants, a sizeable proportion of the primary care workforce managing patients with chronic conditions such as diabetes under varying degree of physician supervision. Further research is warranted to examine knowledge and attitude toward screening guidelines in these primary care specialties.

\section{Policy implications}

In October 2015, USPSTF released an updated recommendation to screen for abnormal glucose (see online supplementary table S1). The 2015 USPSTF screening guidelines differ from other guidelines, in that they will, in 2017, be linked to reimbursement. In particular, under the Affordable Care Act health plans must cover the cost of screening with no copay for patients who have risk factors included in the USPSTF guideline. ${ }^{19}$ While the present study could not assess the impact of the 2015 USPSTF recommendation, as it was finalized while the current study was in progress, the findings of our study may help in understanding how physicians screen and can assist in driving educational activities to increase awareness of these new recommendations to ultimately capture more undiagnosed cases of pre-diabetes and diabetes. For example, study findings indicate that older PCPs 
(35-54 years) and those who do not consider patient's out-of-pocket cost as an important driver influencing their decision to screen are less likely to rely on USPSTF guidelines. Future educational activities could be strategically targeted toward such subgroups of physicians to increase awareness of these new recommendations.

Of additional note is the PCPs' preference for HbAlc as a screening test for pre-diabetes and diabetes. Currently, HbAlc is not reimbursable through Medicare as a screening test, and is only reimbursable through Medicare for patients with established diabetes. ${ }^{20}$ However, due to physicians' preference for the HbAlc screening test, it is possible that coverage of HbAlc, which does not require fasting, may reduce both economic and process barriers for patients at risk for diabetes to receive diabetes screening.

Finally, the present study showed low referral rates for patients with pre-diabetes to DPP programs and for patients with diabetes to DSME/DSMS. Future research should continue to monitor trends in uptake for both and track physician's characteristics and other barriers associated with lower referral rates, as the reimbursement environment, at least around DPP, is likely to change. While not currently a covered program under Medicare, DPP is slated to be covered for beneficiaries in January 2018 with diagnosed pre-diabetes. ${ }^{21}$

Although DSME/DSMS is already covered for newly diagnosed Medicare beneficiaries and Medicare beneficiaries who are at risk for complications from diabetes, ADA/American Association of Diabetes Educators (AADE)/Academy of Nutrition and Dietetics (AND) recently issued a joint statement about the need for ongoing DSME among all patients with diabetes at diagnosis and as needed after that. ${ }^{22}$ It will be of high interest to examine whether coverage for DSME/DSMS will be eventually expanded to cover more hours and all patients with diabetes.

\section{CONCLUSIONS}

This large unique observational hybrid study revealed that many PCPs reported that they rely on USPSTF/ADA

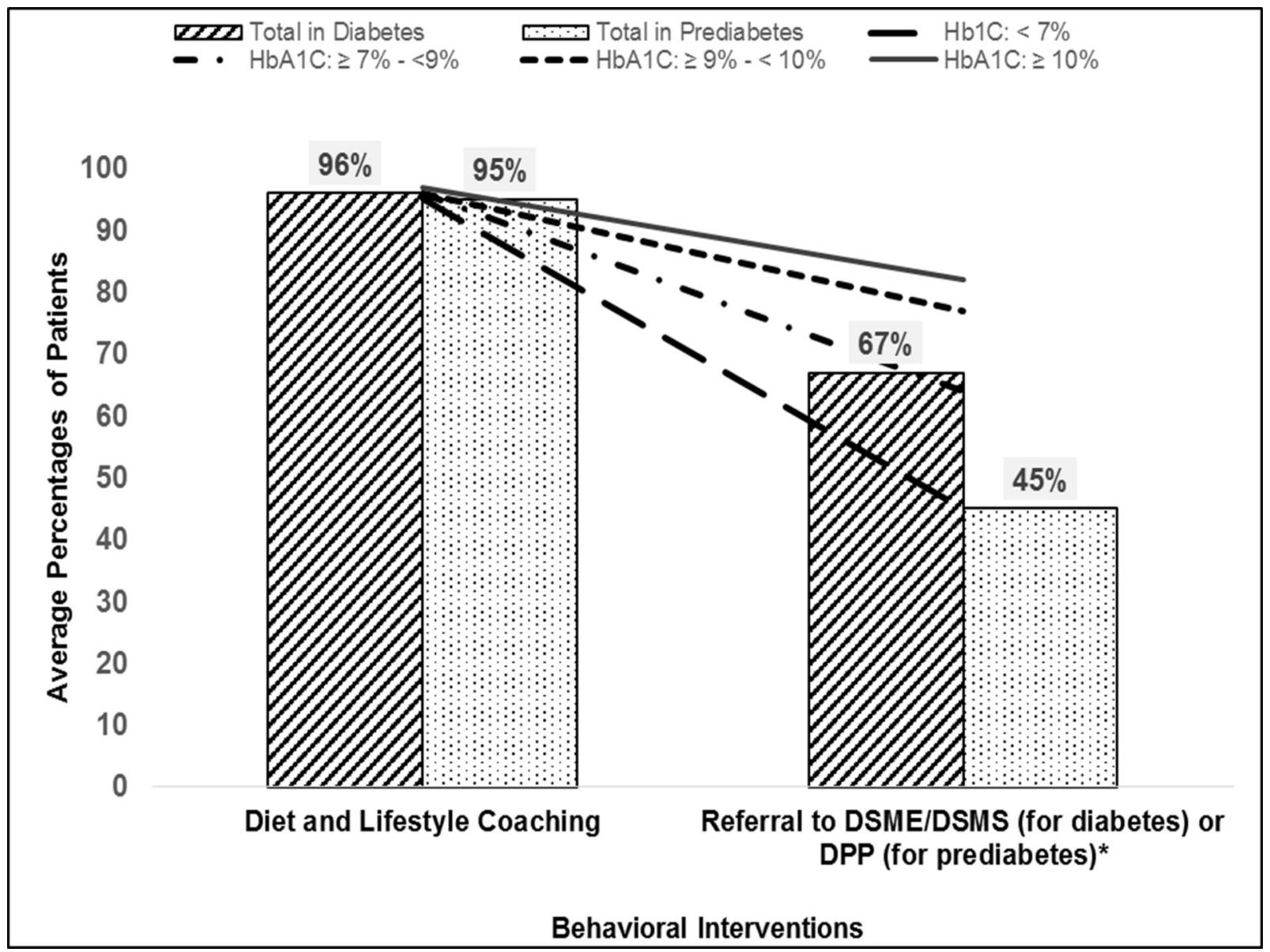

Figure 3 Self-reported physician referral to diabetes prevention and management programs and other non-pharmacological interventions in patients newly diagnosed with pre-diabetes or type 2 diabetes (stratified by severity level). ${ }^{*}$ The lines in the graph represent average percentages of patients at different diabetes severity level (HbA1C level) receiving each intervention, as reported by physician. The average percentages of patients referred to DSME/DSMS and DPP programs are statistically significant across diabetes severity level, at $p$ value $<0.05$. DSME, diabetes self-management education; DSMS, diabetes self-management support; DPP, Diabetes Prevention Program. 
guidelines; however, for about one-third of PCPs this finding was not supported by evidence from EMR data. When asked about the likelihood of screening patients who meet individual criteria in the screening guidelines without revealing that the criteria are part of guidelines, about two-thirds of physicians report that they are quite likely to screen and this was supported by evidence from EMR data. These findings indicate that many physicians rely more on their clinical experience and other sources in decisions to screen, and a gap exists with respect to their self-reported adherence to screening guidelines and real-world practice. Self-reported referral to diabetes prevention and management programs was quite low compared with diet and lifestyle coaching despite the strong evidence base for DPP for preventing/delaying progression to type 2 diabetes and DSME for preventing complications. Study findings emphasize the importance of (A) developing educational efforts to improve the awareness of diabetes screening guidelines, particularly USPSTF's 2015 update which is linked to insurance coverage, (B) improving awareness of reimbursement for $\mathrm{HbA1C}$ as a screening test, as it is convenient to administer and noted by physicians to be their favored screening test; and $(\mathrm{C})$ adoption of quality measures to encourage screening and subsequent appropriate referral to DPP and DSME/Diabetes Self-management Training (DSMT).

Acknowledgements Michelle Krukas, QuintilesIMS, Cathy Liu, QuintilesIMS (when study was conducted) and Elise Kaufman, QuintilesIMS (when study was conducted) assisted with analyzing data. Dr Ray Gani, QuintilesIMS (when study was conducted), provided valuable advice for designing the study. David Varner, QuintilesIMS (when study was conducted), Michelle Hendrickx, QuintilesIMS and Alexandria Portelli, QuintilesIMS (when study was conducted) assisted with physician recruitment.

Contributors SM contributed to conceptualizing and designing of study, analyzing and/or interpreting data, and writing/editing of the manuscript. MM contributed to conceptualizing and designing of study, interpreting data, and writing/editing of the manuscript. TW contributed to conceptualizing and designing of study and reviewed/edited the manuscript. KG contributed to conceptualizing and designing of study and reviewed/edited the manuscript. KMVN contributed to interpreting data and reviewed/edited the manuscript. KL contributed to conceptualizing and designing of study, analyzing and/or interpreting data and writing/editing of the manuscript.

Funding This work was supported by Novo Nordisk, Inc.

Competing interests QuintilesIMS, Inc. designed and conducted this study and developed the manuscript. The study sponsor (Novo Nordisk, Inc.) contributed to conceptualizing and designing of the study, interpretation of data and development of manuscript. SM and KL were employees of QuintilesIMS, Inc. at the time of the study and may hold stock options in QuintilesIMS, Inc. MM, KG and TW were employees of Novo Nordisk, Inc. at the time of the study and may hold stock options in Novo Nordisk, Inc. As per previous sentence, TW is no longer an employee of Novo Nordisk, Inc. KMVN is a consultant for Novo Nordisk, Inc. The authors have indicated they have no other conflicts of interest with regard to the content of this article.

Provenance and peer review Not commissioned; externally peer reviewed. Data sharing statement Additional variables have been measured in this study that are not presented in this article. Information on these variables is available upon request.

Open Access This is an Open Access article distributed in accordance with the Creative Commons Attribution Non Commercial (CC BY-NC 4.0) license, which permits others to distribute, remix, adapt, build upon this work non-commercially, and license their derivative works on different terms, provided the original work is properly cited and the use is non-commercial. See: http://creativecommons.org/ licenses/by-nc/4.0/

C Article author(s) (or their employer(s) unless otherwise stated in the text of the article) 2017. All rights reserved. No commercial use is permitted unless otherwise expressly granted.

\section{REFERENCES}

1. Centers for Disease Control Prevention. National Diabetes statistics report: estimates of diabetes and its burden in the United States. . In Atlanta, GA: US Department of Health and Human Services, Centers for Disease Control Prevention, 2014.

2. Sheehy AM, Flood GE, Tuan W-J, et al. Analysis of guidelines for screening diabetes mellitus in an ambulatory population. Mayo Clinic Proceedings. : Elsevier, 2010:85: 27-35.

3. American Diabetes Association. Economic costs of diabetes in the U.S. in 2012. Diabetes Care 2013;36:1033-46.

4. American Diabetes Association. Standards of medical care in diabetes--2009. Diabetes Care 2009;32 Suppl 1:S13-61.

5. American Diabetes Association. Standards of medical care in diabetes--2010. Diabetes Care 2010;33 Suppl 1:S11-S61.

6. American Diabetes Association. Standards of medical care in diabetes--2014. Diabetes Care 2014;37 Suppl 1:S14-90.

7. US Preventive Services Task Force. Diabetes mellitus (type 2) in adults: screening, 2015.

8. Bullard KM, Ali MK, Imperatore G, et al. Receipt of Glucose Testing and Performance of Two US Diabetes Screening Guidelines, 20072012. PLoS One 2015;10:e0125249.

9. Dall TM, Narayan KM, Gillespie KB, et al. Detecting type 2 diabetes and prediabetes among asymptomatic adults in the United States: modeling American Diabetes Association versus US Preventive Services Task Force diabetes screening guidelines. Popul Health Metr 2014;12:1.

10. Kiefer MM, Silverman JB, Young BA, et al. National patterns in diabetes screening: data from the National Health and Nutrition Examination Survey (NHANES) 2005-2012. J Gen Intern Med 2015;30:612-8.

11. Ealovega MW, Tabaei BP, Brandle M, et al. Opportunistic screening for diabetes in routine clinical practice. Diabetes Care 2004;27:9-12.

12. Fukunaga LL, Uehara DL, Tom T, et al. Perceptions of diabetes, barriers to disease management, and service needs: a focus group study of working adults with diabetes in Hawaii. Prev Chronic Dis 2011;8:A32.

13. Diabetes Prevention Program (DPP) Research Group. The Diabetes Prevention Program (DPP): description of lifestyle intervention. Diabetes Care 2002;25:2165-71.

14. Peyrot M, Rubin RR, Funnell MM, et al. Access to diabetes selfmanagement education: results of national surveys of patients, educators, and physicians. Diabetes Educ 2009;35:246-63.

15. Services MDoHaH: Diabetes SelfIManagement Education Barrier Study. Maine Center for Disease Control and Prevention I Division of Chronic Disease, Diabetes Prevention and Control Program, 2006.

16. Taylor C, Keim KS, Sparrer A, et al. Social and cultural barriers to diabetes prevention in Oklahoma American Indian women. Prev Chronic Dis 2004;1:A06.

17. Hawkins M. A Survey of America's Physicians: Practice Patterns and Perspectives. 2012. Retrieved on Dec 2012.

18. Young A, Chaudhry HJ, Rhyne J, et al. a census of actively licensed physicians in the United States, 2010. Journal of Medical Regulation 2013;99:11-24.

19. Foundation KF. Preventive Services covered by Private Health Plans under the Affordable Care Act: Kaiser Family Foundation, 2015.

20. Reminder- Medicare Provides Coverage of Diabetes Screening Tests

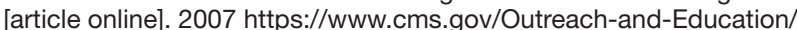
Medicare-Learning-Network-MLN/MLNMattersArticles/downloads/ se0821.pdf (accessed 1 Dec 2016).

21. Medicare Diabetes Prevention Program Expansion [article online] 2016 https://www.cms.gov/Newsroom/MediaReleaseDatabase/ Fact-sheets/2016-Fact-sheets-items/2016-07-07.html.

22. Diabetes self-management training [article online]. https://www. medicare.gov/coverage/diabetes-self-mgmt-training.html (accessed November 30,2016$)$. 